\title{
Monoclonal antibodies in the treatment of multiple myeloma
}

\author{
Paul G. Richardson, ${ }^{1}$ Sagar Lonial, ${ }^{2}$ Andrzej J. Jakubowiak, ${ }^{3}$ Jean-Luc Harousseau ${ }^{4}$ and Kenneth C. Anderson ${ }^{1}$
}

${ }^{1}$ Dana-Farber Cancer Institute, Boston, MA, USA, ${ }^{2}$ Department of Hematology and Medical Oncology, Winship Cancer Institute, Emory University School of Medicine, Atlanta, GA, USA, ${ }^{3}$ University of Michigan Comprehensive Cancer Center, Ann Arbor, MI, USA, and ${ }^{4}$ Centre Rene Gauducheau, Nantes, France

\section{Summary}

Despite recent advances in treatment that have significantly improved overall survival, multiple myeloma (MM) remains incurable. Although rituximab, the first monoclonal antibody (MAb) evaluated in MM treatment, provided only very limited benefit, research is ongoing into a number of other MAbs directed against a variety of MM-related target antigens. Given the inherent immune dysfunction associated with MM, newer strategies that may enhance immune function in conjunction with antibodies may also provide a more fruitful clinical approach. Potential MAb targets in MM include growth factors and their receptors, other signalling molecules, and antigens expressed exclusively or predominantly on MM cells. MAb therapy involves a range of mechanisms, including antibody-dependent cellular cytotoxicity, complement-dependent cytotoxicity, interference with receptor-ligand interactions, and MAb conjugation to radioisotopes or toxins. The antigens currently targeted in MM therapy are discussed, along with the development status of the corresponding MAb therapeutics. Elotuzumab, an anti-CS1 MAb, has recently achieved clinically meaningful responses when combined with lenalidomide or bortezomib in patients with relapsed and relapsed/refractory MM. Other MAbs are also showing early promise. More ongoing clinical research is required to identify optimal combination regimens and biomarkers that may help predict response to specific MAb-based combinations.

Keywords: multiple myeloma, monoclonal antibodies, novel therapies, novel targets, targeted therapies.

Multiple myeloma (MM) is a malignancy of plasma cells and represents about $15 \%$ of newly-diagnosed haematological cancers in the USA; specifically, about 20000 new MM cases are diagnosed each year, with $\mathrm{MM}$ accounting for more than

Correspondence: Paul G. Richardson, MD, Dana-Farber Cancer Institute, 44 Binney St, Dana 1B02, Boston, MA 02115, USA.

E-mail: paul_richardson@dfci.harvard.edu
10000 fatalities annually (Jemal et al, 2010). Prior to the introduction of chemotherapy using the alkylating agent melphalan (in combination with prednisone) in the early 1960s, median survival in MM was < 1 year after diagnosis; melphalan-prednisone combination therapy improved the median survival to 2-3 years at best (Kumar et al, 2008; San Miguel et al, 2008). Since then, clinical advances in MM therapy have included the use of high-dose chemotherapy supported by autologous stem cell transplantation (ASCT) in the mid-1990s; the development of bisphosphonates for the treatment of MM-related bone disease; the introduction of thalidomide as MM therapy in the late 1990s; the approval of the first-in-class proteasome inhibitor bortezomib in 2003; and the later introduction of the second generation immunomodulatory drug $\left(\mathrm{IMiD}^{\circledR}\right.$ ) lenalidomide in 2005 (Kumar et al, 2008; Mhaskar et al, 2010).

These therapeutic advances, particularly the introduction of bortezomib, thalidomide, and lenalidomide, have led to clinically significant increases in overall survival (OS). For example, a retrospective study of 2981 Mayo Clinic patients showed that median OS from date of diagnosis was 29.9 months [95\% confidence interval (CI) 28.3-31.6 months] for patients diagnosed prior to December 1996, compared with 44.8 months (95\% CI 39.6-50.0 months) for those diagnosed between January 1997 and December 2006 (Fig 1) (Kumar et al, 2008).

The observed gains in OS were achieved primarily by younger patients: for patients $\leq 65$ years at diagnosis, median OS was 60 months for diagnoses between 1997 and 2006 and 33 months for diagnoses prior to 1997; in contrast, for patients $>65$ years at diagnosis, median OS was 32 months and 26 months for diagnoses between 1997 and 2006 and prior to 1997, respectively. OS gains were particularly important among patients who relapsed following ASCT, and these increases are clearly attributable to the introduction of novel agents, and in the case of this study predominantly thalidomide and lenalidomide (Fig 2). During the past decade, median OS among patients who received 1 or more of the newer drugs after postASCT relapse was 30.9 months (95\% CI 23.6-38.2 months), compared to $14 \cdot 8$ months (95\% CI $11 \cdot 3-18 \cdot 4$ months) for those who did not $(P<0 \cdot 001)$ (Kumar et al, 2008). 


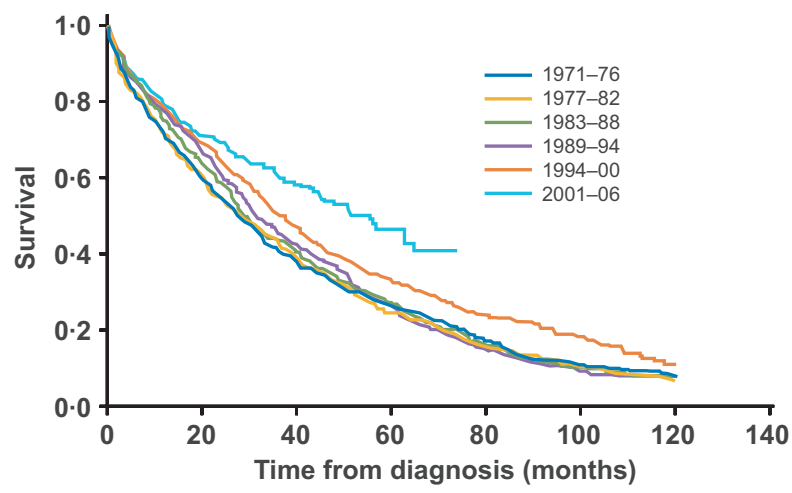

Fig 1. Improvements in multiple myeloma overall survival following diagnosis, 1971-2006.Source: Blood by American Society of Hematology. Copyright 2008 Reproduced with permission of American Society of Hematology (ASH) in the format Journal via Copyright Clearance Center.
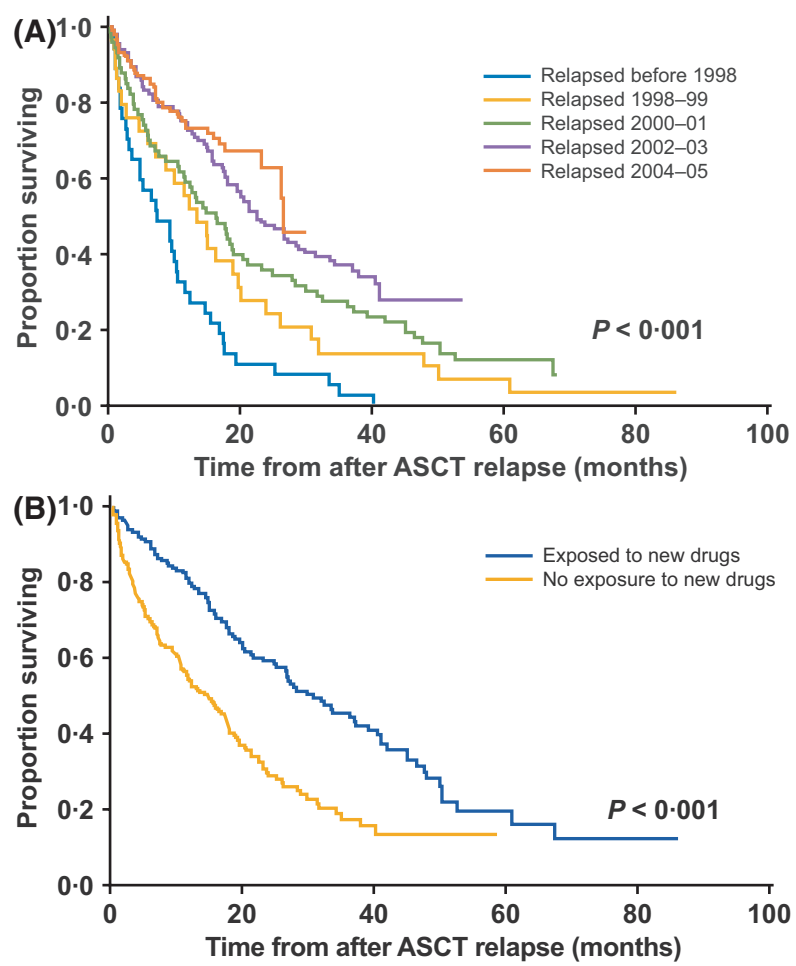

Fig 2. Improvements in multiple myeloma overall survival following relapse after autologous stem cell transplantation.Source: Blood by American Society of Hematology. Copyright 2008 Reproduced with permission of American Society of Hematology (ASH) in the format Journal via Copyright Clearance Center.

A similar pattern of improvements in OS was observed in a Swedish study of MM therapy, in which patients were stratified by date of diagnosis and age at diagnosis (Kristinsson et al, 2007). Across all age groups, 1-year survival improved significantly among patients diagnosed during 1994-2003 compared with those diagnosed during 1973-1979 and 19801986. However, as with the Mayo Clinic study, significant improvements in 5-year and 10-year survival were confined to patients younger than 60 years and 70 years at diagnosis, respectively.

Despite these documented improvements in OS, MM remains incurable in the vast majority of patients. Although MM has become a more treatable disease, the development of resistant/refractory disease is inevitable, and leads to death. Thus, an urgent need remains for therapies that can further extend disease control, potentially achieving longer term remission in patients with $\mathrm{MM}$, and ideally without the addition of significant treatment-related toxicities.

In addition to the established use of thalidomide, lenalidomide, and bortezomib-based combination therapies (Richardson et al, 2007), a number of new targeted agents, developed on the basis of disease biology, are being pursued both as monotherapy and in combination with established treatment options (Table I). These include second generation proteasome inhibitors (such as carfilzomib) and third generation immunomodulatory drugs (specifically pomalidomide) (Jagannath et al, 2010); inhibitors of histone deacetylase (vorinostat, panobinostat, romidepsin), heat shock protein 90 (tanespimycin), Akt (perifosine), and kinesin spindle protein (KSP; ARRY-520) (Jagannath et al, 2010; Shah et al, 2010; Niesvizky et al, 2011); enhancers of natural immune surveillance using vaccination or dendritic cell infusion (Rosenblatt et al, 2011); and a range of monoclonal antibodies (MAb) directed at mediators of MM cell survival, tumour progression, and interactions with the bone marrow (BM) microenvironment.

This review focuses on the role of MAb therapy in MM, describing potential targets and agents currently in development. We examine targets and MAbs that have demonstrated a high level of cytotoxicity/efficacy against MM in preclinical and clinical studies.

\section{Monoclonal antibody therapy in multiple myeloma}

\section{General considerations}

A wide range of antigens may ultimately be targeted in MM therapy, including those involved in cell survival, anti-apoptotic pathways, cell-to-cell communication, angiogenesis, and interactions between MM cells and bone marrow stromal cells (BMSCs) and/or other cells in the BM microenvironment (Kastritis et al, 2009; Di Bernardo et al, 2010). These potential targets include signalling molecules, cell surface receptors and other cell surface proteins, plasma cell growth factors, and mediators of adhesion. Ideally, a useful target for MAb-based MM therapy should be expressed exclusively on a majority of MM cells (or other target cells such as those involved in angiogenesis), or to a much higher level than on non-target cells (Di Bernardo et al, 2010).

Effective MAb-based MM therapy may involve a number of potential mechanisms, including direct cytotoxic effects and 
Table I. Selected novel therapies in development for treatment of multiple myeloma (excluding monoclonal antibodies).

\begin{tabular}{|c|c|c|c|c|}
\hline Name (Brand name) & Developer & Type & Status* & Regimen \\
\hline Carfilzomib & $\begin{array}{l}\text { Onyx Pharmaceuticals, San } \\
\text { Francisco, CA, USA }\end{array}$ & Proteasome Inhibitor & Phase 3 enrolling & + lenalidomide + dexamethasone \\
\hline Pomalidomide & $\begin{array}{l}\text { Celgene Corporation, Summit, } \\
\text { NJ, USA }\end{array}$ & $\mathrm{IMiD}^{\circledR}$ & Phase 3 enrolling & $\begin{array}{l}\text { Monotherapy } \\
+ \text { dexamethasone }\end{array}$ \\
\hline Vorinostat $\left(\right.$ Zolinza $\left.^{\circledR}\right)$ & $\begin{array}{l}\text { Merck \& Co., Inc., Whitehouse } \\
\text { Station, NJ, USA }\end{array}$ & HDAC inhibitor & Phase 3 ongoing & + bortezomib \\
\hline Panobinostat & $\begin{array}{l}\text { Novartis Oncology, East } \\
\text { Hanover, NJ, USA }\end{array}$ & HDAC inhibitor & Phase 3 enrolling & + bortezomib + dexamethasone \\
\hline Romidepsin & Celgene Corporation & HDAC inhibitor & Phase 2 ongoing & $\begin{array}{l}\text { Monotherapy } \\
+ \text { bortezomib }\end{array}$ \\
\hline Perifosine & $\begin{array}{l}\text { Keryx Biopharmaceuticals, New } \\
\text { York, NY, USA }\end{array}$ & Akt inhibitor & Phase 3 ongoing & + bortezomib + dexamethasone \\
\hline Arry-520 & $\begin{array}{l}\text { Array Biopharma, Boulder, CO, } \\
\text { USA }\end{array}$ & KSP inhibitor & $\begin{array}{l}\text { Phase } 1 / 2 \text { enrolling } \\
\text { Phase } 1 \text { enrolling }\end{array}$ & $\begin{array}{l}\text { Monotherapy } \\
+ \text { bortezomib + dexamethasone }\end{array}$ \\
\hline
\end{tabular}

HDAC, histone deacetylase; Hsp, heat shock protein; IMiD ${ }^{\circledR}$, immunomodulatory drug; KSP, kinesin spindle protein.

${ }^{*}$ In most advanced clinical trial(s).

interference with cell-cell interactions. The most commonly observed cytotoxic mechanisms in preclinical and early clinical studies are antibody-dependent cellular cytotoxicity (ADCC) and complement-dependent cytotoxicity (CDC). Other possible mechanisms include interference with ligand binding (e.g. growth factor or G-protein coupled receptors) and the use of MAbs as targeted 'carriers' of cytotoxic agents. The latter mechanism may be especially useful as a way of conveying intracellular toxins (in the case of MAbs that are internalized) or radioactive isotopes, which may have cytotoxic effects that extend beyond cells bearing specific MAb targets (Weiner et al, 2010).

\section{Rituximab in $M M$}

The earliest evaluations of MAb therapy targeting MM were based on the success of rituximab, an antibody to the B-cell specific antigen CD20, in the treatment of lymphoma. Rituximab was the first MAb approved for any cancer therapy, and is currently indicated for treatment of chronic lymphocytic leukaemia and non-Hodgkin lymphoma (http://www. gene.com/gene/products/information/pdf/rituxan-prescribing. pdf). Rituximab exhibits impressive activity in these disease states, especially in combination with cytotoxic chemotherapy and as maintenance therapy (Kapoor et al, 2008; Salles et al, 2011).

However, clinical studies of rituximab therapy in MM have generally been disappointing, with few patients achieving only minimal responses (MR) (Kapoor et al, 2008). The failure of rituximab in this setting is potentially attributable to the small number of MM patients (estimated at 13-22\%) who express CD20 in primarily a low proportion of plasma cells. Another mechanism that may render MM refractory to rituximab is the possibility that MM cells express increased levels of comple- ment-inhibiting proteins, reducing the effectiveness of CDC. In addition, Fc- $\gamma$ receptor polymorphism may limit the effectiveness of ADCC as a killing mechanism. Finally, the use of rituximab in MM may induce a selective loss of CD20 expression.(Kapoor et al, 2008) Although it is conceivable that rituximab may be useful in certain carefully-selected MM patients, such as $\mathrm{t}(11 ; 14)$ translocation patients, who exhibit relatively high CD20 expression (Robillard et al, 2003), it is unlikely to be of value in the majority of MM cases.

\section{Novel targets and MAbs in development}

A number of other potential antigen targets are being investigated in the context of MM therapy, and several have reached clinical trials. Some of the most promising MMrelated antigen targets are described here, along with the corresponding MAb therapeutics in development (Table II).

Interleukin-6 (IL-6). IL-6 has been recognized as a key cytokine in the development and progression of MM, exerting anti-apoptotic activity and multiple additional effects within the BM. IL- 6 is produced predominantly by BMSCs, and is upregulated by multiple cytokines (Kastritis et al, 2009). Both IL-6 and its receptor, IL-6R, are potential targets for MAb-based intervention.

A chimeric anti-IL-6 MAb, siltuximab (CNTO 328), enhances dexamethasone-induced cytotoxicity in MM cell lines and in MM cells from patients refractory to dexamethasone therapy; it also enhances the cytotoxicity of the bortezomib plus dexamethasone combination (Trikha et al, 2003; Voorhees et al, 2009). Siltuximab has demonstrated activity in the lymphoproliferative disorder Castleman's disease (van Rhee et al, 2010), and is currently being evaluated in $\mathrm{MM}$ in multiple single-arm and randomized 


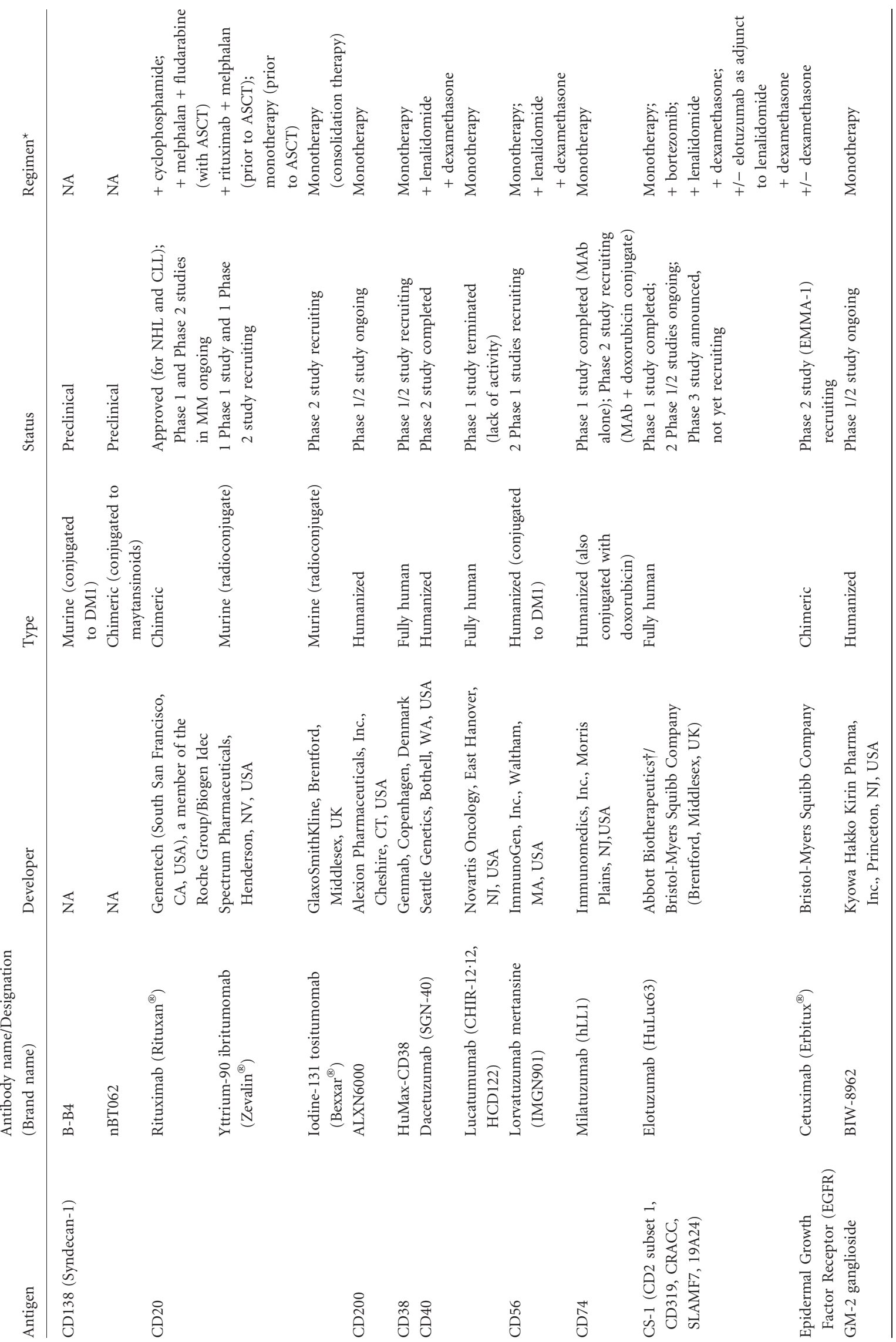




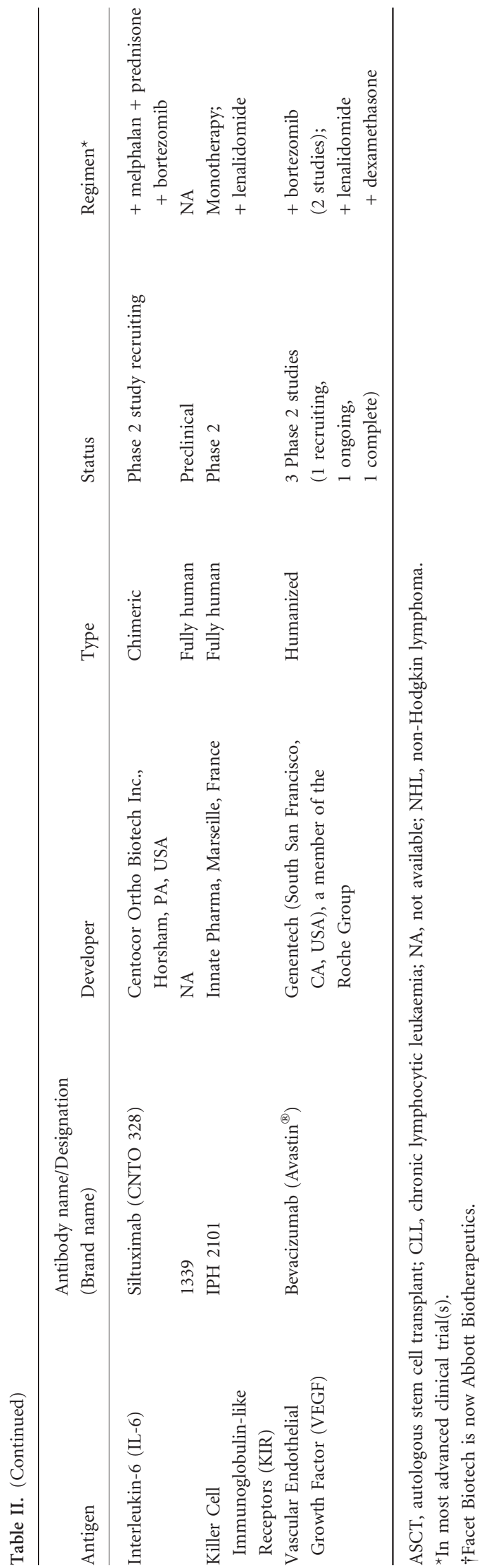

Phase 2 studies, either alone or in combination with bortezomib (NCT01219010, NCT00402181, NCT00911859, NCT00412321, NCT00401843). Preliminary results in combination with bortezomib have shown promise, with a $57 \%$ objective response rate (ORR), although grade $3+$ haematological toxicities were somewhat common (Rossi et al, 2008). A Phase 3 study of siltuximab or placebo in combination with bortezomib and dexamethasone is underway (NCT01266811).

A murine anti-IL-6 MAb, BE- 8 , has been evaluated in combination with dexamethasone and high-dose melphalan as a conditioning regimen for ASCT; the combination induced a response in 13 of 16 patients $(81 \%)$ and a complete response (CR) in 6 patients $(37 \cdot 5 \%)$. The overall response (OR) was similar to historical controls by the same group of high-dose melphalan; however, the CR rate appeared to be higher, and was correlated with IL-6 neutralization (Moreau et al, 2000). In a subsequent prospective, multicentre randomized trial by the same group, the addition of BE- 8 to the melphalan plus dexamethasone conditioning regimen showed no improvement in response or survival rates for patients with high-risk MM (Moreau, et al 2006).

Tocilizumab is a humanized anti-IL-6 MAb currently approved for rheumatoid arthritis in several countries and for Castleman disease in Japan. Tocilizumab has demonstrated efficacy in a murine MM model (Yoshio-Hoshino et al, 2007) and is currently being evaluated clinically in MM. Another anti-IL-6 MAb, 1339, has demonstrated activity on MM cell lines (co-cultured with BMSCs) in vitro, and in murine xenograft MM models; it is not yet being evaluated clinically (Fulciniti et al, 2009a).

Vascular endothelial growth factor (VEGF). VEGF is a key cytokine that promotes angiogenesis in a variety of tumour types, facilitating improved blood flow that is critical to tumour cell survival (Veikkola et al, 2000). Bevacizumab, a humanized anti-VEGF MAb, is currently indicated for treatment of colorectal cancer (http://www.gene.com/gene/ products/information/pdf/avastin-prescribing.pdf). In a Phase 2 study in patients with relapsed/refractory MM, seven of 10 patients responded [partial response $(\mathrm{PR})$ ] to bevacizumab in combination with low-dose dexamethasone and lenalidomide (Raschko et al, 2007). An additional Phase 2 study of the same combination reported similar results in a larger patient population (OR 19/27, 70\%) (Callander et al, 2009), noting that this response rate was not significantly different from that seen in the pivotal Phase 3 trial of lenalidomide plus dexamethasone (61\%) (Weber et al, 2007). An additional Phase 2 study of this combination is currently recruiting patients (NCT00410605) and the drug is also being evaluated in combination with bortezomib (NCT00464178, NCT00473590).

CD40. CD40 is a member of the tumour necrosis factor (TNF) receptor superfamily that is highly expressed on MM cells and on BMSCs (Tai et al, 2002, 2003). The activation of 
CD40 by its ligand (CD40L) induces a range of biological effects, including MM cell proliferation and migration, mediated primarily via the PI3K/AKT pathway, and induction of VEGF overexpression. VEGF overexpression is especially pronounced in MM cells with mutated TP53, and VEGF also stimulates production of IL- 6 by BMSCs (Tai et al, 2002, 2003).

Two anti-CD40 antibodies, dacetuzumab (SGN-40) and lucatumumab (CHIR-12·12, HCD122), have been evaluated in preclinical studies. SGN-40 is a humanized anti-CD40 MAb that induces cell death and/or growth arrest in MM cell lines; among other effects, dacetuzumab down-regulates IL-6R, rendering cell lines unresponsive to IL-6 stimulation (Tai et al, 2004). Cell line studies and a Phase 1 monotherapy study have shown that the primary cytotoxic mechanisms appear to be induction of apoptosis (potentially related to IL-6R suppression) and ADCC (Hayashi et al, 2003; Tai et al, 2004). The observation that SGN-40-induced MM cell death is enhanced by lenalidomide (Tai et al, 2005a) led to its evaluation in a Phase 1 study in combination with lenalidomide and dexamethasone in patients with relapsed or refractory MM; an OR of 39\% (13/36) was seen, with some activity noted in patients receiving prior lenalidomide (Agura et al, 2009).

Lucatumumab is a fully human anti-CD40 MAb that inhibits MM cell growth in vitro, even when MM cells are cocultured with BMSCs. Animal studies have shown that the primary cytotoxic mechanism is ADCC (Tai et al, 2005b). Lucatumumab has been found to inhibit multiple pathways that are induced by CD40L binding to CD40, including AKT phosphorylation and signalling and $\mathrm{MM}$ cell adhesion to BMSCs and to fibronectin, in addition to suppression of IL-6 and VEGF (Tai et al, 2005b). However, a Phase 1 study of lucatumumab in patients with relapsed/refractory MM was terminated because of minimal biological and clinical activity (NCT00231166).

CD74. CD74 is a transmembrane protein that forms the invariant portion of HLA-DR; it is expressed on MM cells in a majority of patients. Because CD74 exists in a dynamic pool and is rapidly internalized, an anti-CD74 antibody might be useful as a carrier for cytotoxins (Burton et al, 2004). This approach is being employed with milatuzumab (hLL1), a humanized anti-CD74 MAb coupled with the anthracycline doxorubicin to form a conjugated antibody designated IMMU-110 (Sapra et al, 2005). In cell line and mouse xenograft experiments, IMMU-110 demonstrated high activity against $\mathrm{MM}$, and it also appeared to be safe in a monkey model of MM (Sapra et al, 2005). IMMU-110 is being evaluated in a Phase 1/2 study (NCT00421525), and a Phase 2 study is currently ongoing (NCT01101594).

CD56. CD56 (neural cell adhesion molecule, NCAM) is expressed on neurons, muscle cells, and a variety of tumours, including MM; it appears to mediate cell adhesion, migration, and invasion (Mechtersheimer et al, 1992; Lutz \& Whiteman, 2009). Lorvotuzumab mertansine (IMGN901), an immunoconjugate composed of a humanized MAb to CD56 (huN901) conjugated to the maytansinoid DM1, has shown activity against MM cell lines (Tassone et al, 2004a; Lutz \& Whiteman, 2009). Two Phase 1 studies (one as monotherapy, one in combination with lenalidomide and dexamethasone) are currently recruiting patients (NCT00346255, NCT00991562).

CD38. CD38 is a glycoprotein found on the surface of many immune system cells, including MM cells (Stevenson, 2006). A human anti-CD38 MAb, HuMax-CD38, has demonstrated preclinical activity against MM cell lines and patient-derived MM cells, with cytotoxic effects that involve both ADCC and CDC (Stevenson, 2006). HuMax-CD38 is being evaluated in a Phase $1 / 2$ safety study in patients with relapsed or refractory MM that is currently recruiting participants (NCT00574288). Results of this preliminary study are awaited with interest, with early reports suggesting favourable tolerability and disease stabilization in some patients.

CD138 (Syndecan-1). CD138 is a cell surface heparin sulphate proteoglycan, highly expressed on plasma cells and MM cells, that is involved in cell adhesion and maturation (Tassone et al, 2004a; Ikeda et al, 2009). Two different MAbs conjugated to cytotoxic maytansinoid derivatives (which disrupt microtubule assembly) have been evaluated in preclinical studies. B-B4 is a murine MAb against CD138 that has been conjugated to the maytansinoid DM1; it is cytotoxic in vitro to MM lines, and to MM lines and patient-derived MM cells in mouse xenograft models (Tassone et al, 2004b). BT062 is a chimeric MAb conjugated to maytansinoid derivatives that demonstrates in vitro cytotoxicity and inhibition of $\mathrm{MM}$ cells in mouse xenograft models, apparently via apoptotic mechanisms; BT062 also inhibits the adherence of MM cells to BMSCs and abrogates the protective effects exerted by growth factors and BMSCs on MM cells (Ikeda et al, 2009). A Phase 1 dosefinding study of BT062 for patients with relapsed/refractory MM is underway (NCT00723359), and an additional Phase 1/ 2a study is recruiting patients with advanced MM (NCT01001442).

GM-2 ganglioside. GM-2 is a ganglioside expressed on MM cells. A humanized anti-GM-2 MAb, BIW-8962, has demonstrated in vitro killing of MM cell lines and in vivo effectiveness in mouse xenograft models, with ADCC and CDC the most prominent cytotoxic mechanisms (Ishii et al, 2008). BIW-8962 is being evaluated as monotherapy in a Phase $1 / 2$ study for patients with relapsed/refractory MM (NCT00775502).

CD200. CD200 is a highly conserved transmembrane glycoprotein expressed on a wide range of cell types; however, expression of the receptor for CD200 (CD200R1) is 
apparently limited to antigen-presenting cells of myeloid lineage and certain T-cell populations, and is thought to deliver inhibitory signals. The expression of the CD200 gene by MM cells has been found to be a predictor of poor prognosis in patients with MM (Moreaux et al, 2006). ALXN6000 is a humanized anti-CD200 MAb that is currently being evaluated in a Phase $1 / 2$ study in patients with $\mathrm{MM}$ or B-cell CLL (NCT00648739), with results expected in the near future.

Killer cell immunoglobulin-like receptors (KIR). KIRs are receptors expressed on natural killer (NK) cells and a subset of $\mathrm{T}$ cells and function as key regulators of NK cell activity (Campbell \& Purdy, 2011). Several studies are currently underway in smouldering and first relapse MM (NCT01222286, NCT01217203, NCT00999830, NCT01248455), and safety and tolerability results are expected later in 2011 for a Phase 1 study in relapsed or refractory MM (NCT00552396).

CS1 (CD2 subset 1, CD319, CRACC, SLAMF7, 19A24). CS1 is a cell surface glycoprotein universally expressed at high levels on MM cells but with limited expression on normal cells (Hsi et al, 2008; Tai et al, 2008). The function of CS1 is not well characterized, but it appears to play a critical role in interactions between MM cells and BMSCs (Tai et al, 2008). Its expression pattern suggests that it may be an attractive target for MAb therapy in MM. Elotuzumab (HuLuc63) is a fully humanized MAb against CS1 that has shown significant in vitro activity as monotherapy against patient-derived $\mathrm{MM}$ cell lines, and in vivo activity in a mouse MM xenograft model (Tai et al, 2008). These studies showed that elotuzumab-induced cell death was mediated primarily via ADCC, and that elotuzumab was active even in MM cells refractory to conventional and targeted therapies (Tai et al, 2008).

Elotuzumab has also been evaluated in Phase 1 and Phase 2 clinical studies in patients with relapsed/refractory MM. In a Phase 1 monotherapy study, elotuzumab demonstrated acceptable toxicity but its antitumour activity was only modest: no responses were seen, although elotuzumab did induce stable disease (SD) in six of 19 patients (Zonder et al, 2008).

Despite the limited activity of elotuzumab monotherapy, preclinical data suggested that combinations of elotuzumab with novel agents (specifically bortezomib and lenalidomide) acted synergistically, enhancing ADCC in both cell line and xenograft models (Tai et al, 2008; van Rhee et al, 2009). Clinical studies of elotuzumab combined with either lenalidomide plus dexamethasone or with bortezomib were therefore initiated and are showing considerable promise. In a preliminary analysis of an ongoing Phase 1 study of elotuzumab plus bortezomib, the ORR (PR or better) was $48 \%$ of 27 evaluable patients, and responses were achieved in several bortezomib-refractory patients; a clinical response ( $\geq \mathrm{MR})$ was seen in 17/27 (63\%) patients. The response rate was lower among heavily-pretreated patients ( $\geq 3$ prior therapies) and the median time to progression was $9 \cdot 46$ months (Jakubowiak et al, 2010).

In a preliminary analysis of an ongoing Phase $1 \mathrm{~b}$ combination study with lenalidomide and dexamethasone, the ORR was $82 \%$ for all treated patients $(N=28), 96 \%$ for lenalidomide-naïve patients $(n=22)$, and $82 \%$ among patients who had been refractory to their most recent treatment $(n=11)$ (Lonial et al, 2010). In a Phase 2 study of the same combination, the ORR was $85 \%$ for evaluable patients (22/ 26), and the remaining four patients had SD; $31 \%$ achieved either a CR or very good partial response (Richardson et al, 2010). For both studies, adverse events (AEs) were primarily infusion-related, and appeared to be readily manageable using adequate premedication.

Elotuzumab is therefore the first MAb in combination with either bortezomib or lenalidomide and dexamethasone to demonstrate clinically meaningful efficacy in relapsed/refractory MM. It is also an excellent example of rational design of combination therapies. In particular, given the modest results observed with monotherapy, further drug development may have been stopped if it were not for preclinical research demonstrating synergy in combination with bortezomib or the lenalidomide/dexamethasone combination. Across all clinical studies to date, most AEs attributable to elotuzumab included mild to moderate infusion reactions, and the implementation of more aggressive premedication regimens appeared to reduce the rate of infusion-related AEs (Zonder et al, 2008; Lonial et al, 2010; Richardson et al, 2010).

\section{Monoclonal antibody therapy for myeloma- related end-organ complications}

In addition to therapy directed at MM cells and tumourpromoting interactions, some efforts have been devoted to MAb therapy directed against the development of end-organ complications; to date, these efforts have been restricted to the suppression of myeloma-related bone disease.

\section{RANK ligand (RANKL)}

RANKL promotes bone loss in osteoporosis and contributes to the development of bone lesions in MM. The inhibition of RANKL may directly impact myeloma cells that express RANK and have a therapeutic role in the treatment of MM. The fully human anti-RANKL MAb, denosumab, has demonstrated some efficacy in a Phase 2 study of patients with plateau-phase or relapsed MM, including suppression of the bone turnover marker serum C-terminal telopeptide of type 1 collagen (sCTx) (Vij et al, 2009). Denosumab is currently being compared with zoledronic acid (the standard of care for prevention of bone disease in several cancers) in patients with advanced cancers or MM in a randomized Phase 3 trial (NCT00330759); results in the MM cohort have thus far been mixed although positive in other cancers; future trials are planned in MM to better define its role. 


\section{Dickkopf-related protein 1 (DKK1)}

DKK1 facilitates the development of bone lesions in MM, primarily by inhibiting the activity of osteoblasts. A fully human anti-DKK1 MAb, BHQ880, has demonstrated improvement in bone parameters in murine models, and also appears to have direct effects on MM cell growth, possibly via interactions with BMSCs and IL-6 related pathways (Fulciniti et al, 2009b; Heath et al, 2009). BHQ880 is being evaluated in combination with zoledronic acid in a Phase 2 study in patients with relapsed/refractory MM (NCT00741377), and studies in early MM (i.e, smouldering MM) are also underway.

\section{The role of monoclonal antibodies in multiple myeloma management}

MM exhibits a number of potentially valuable targets for MAb therapy that await further investigation in clinical studies. As has been the case with other cancers, MAbs, when employed as monotherapy in MM, have generally not produced impressive levels of response with respect to either response rates or extent of response in individual patients. However, preclinical results in MM cell lines and murine explant models, and preliminary clinical results in patients with relapsed/refractory MM suggest that MAbs are likely to act synergistically with traditional therapies (dexamethasone), immune modulators (thalidomide, lenalidomide), and other novel therapies (such as the first-in-class proteasome inhibitor bortezomib); in addition, MAbs have shown the ability to overcome resistance to these therapies. These observations suggest that future work may be most productively directed at the rational development of multi-agent therapies incorporating specific MAbs on the basis of clinical trial results and, possibly, on the identification of patient-specific MM disease factors. To that end, response assessments in future clinical studies may incorporate biomarker evaluations to identify patient subsets that are most likely or unlikely to respond to specific MAbs.

The current model for the development and approval of novel cancer therapies involves a potential paradox, in that they are initially evaluated in patients with late-stage, metastatic, relapsed, and/or refractory disease; and only if activity is shown in these patients relative to existing standards of care are they likely to be evaluated in the treatment of early-stage disease. However, advanced malignancies are extremely challenging therapeutic targets (Rothenberg et al, 2003), involving extensive genetic heterogeneity and multiple resistance mechanisms; while targeted therapies, by definition, are directed against individual components or pathways (albeit with potentially pleiotropic effects). Therefore, the activity of novel targeted therapies (including MAbs) is likely to be greatest against early-stage disease that possesses far fewer mechanisms for resistance or escape. Evaluating novel therapies in earlier stage disease may therefore be beneficial with respect to identifying potentially useful agents that fail to show measurable activity against more advanced disease.

The natural history of MM, now well understood as a progression from monoclonal gammopathy of undetermined significance (MGUS) to asymptomatic (smouldering) MM, and then to symptomatic MM, often with extramedullary progression in the advanced and late stage setting, may afford additional targets for MAb therapy. As yet, treatment is not recommended for MGUS, and options are limited (e.g. bisphosphonate alone) in smouldering MM, as potential toxicities may outweigh the potential benefits. Future research should be directed at further elucidation of the molecular events involved in progression from MGUS to symptomatic $\mathrm{MM}$, and the identification of targets that may prevent or reduce the risk of disease progression, for which MAbs, as an example and given their favourable side effect profile, may have a potential role.

\section{Conclusions}

MAb therapy for MM remains early in its development. As yet, it remains to be defined how MAb therapy can most productively be incorporated into the current therapeutic paradigms that have achieved significant survival gains in patients with MM. However, based on preclinical and preliminary clinical evaluation, as well as MAb therapy experience in other cancers, it is apparent that MAb therapy will probably be most effective when combined with existing MM therapies and, in particular, novel agents. The results of ongoing and future clinical studies of MAb therapy in MM should help identify rational combination strategies that produce improved patient outcome. This should be reflected both in terms of increased OS and of quality of life, given the favourable tolerability profile and the remarkable response rates and durations seen to date.

\section{Acknowledgements}

All authors contributed to the concept and design of the review, the interpretation of the data, and the drafting and critical revision of the manuscript. All authors approved the final manuscript version for publication. The authors would like to thank Stephen Collins, MS, and Ted Everson, PhD, who provided medical writing services, funded by Bristol-Myers Squibb.

\section{References}

Agura, E., Niesvizky, R., Matous, J., Munshi, N., Hussein, M., Parameswaran, R.V., Tarantolo, S.,
Whiting, N.C., Drachman, J.G. \& Zonder, J.A. (2009) Dacetuzumab (SGN-40), lenalidomide, and weekly dexamethasone in relapsed or refractory multiple myeloma: multiple responses observed in a phase 1b study. Blood (ASH Annual Meeting Abstracts), 114, Abstract 2870.

Burton, J.D., Ely, S., Reddy, P.K., Stein, R., Gold,

D.V., Cardillo, T.M. \& Goldenberg, D.M. (2004) 
CD74 is expressed by multiple myeloma and is a promising target for therapy. Clinical Cancer Research, 10, 6606-6611.

Callander, N.S., Markovina, S., Juckett, M.B., Wagner, E., Kolesar, J., Longo, W., Williams, E.C., Kim, K., Werndli, J. \& Miyamoto, S. (2009) The addition of bevacizumab (B) to lenalidomide and low dose dexamethasone does not significantly increase response in relapsed or refractory multiple myeloma (NCI\#7317). Blood (ASH Annual Meeting Abstracts), 114, Abstract 3885.

Campbell, K.S. \& Purdy, A.K. (2011) Structure function of human killer cell immunoglobulinlike receptors: lessons from polymorphisms, evolution, crystal structures and mutations. Immunology, 132, 315-325

Di Bernardo, A., Macor, P., Guarnotta, C., Franco, G., Florena, A.M., Tedesco, F. \& Tripodo, C. (2010) Humoral immunotherapy of multiple myeloma: perspectives and perplexities. Expert Opinion on Biological Therapy, 10, 863-873.

Fulciniti, M., Hideshima, T., Vermot-Desroches, C. Pozzi, S., Nanjappa, P., Shen, Z., Patel, N., Smith, E.S., Wang, W., Prabhala, R., Tai, Y.T., Tassone, P., Anderson, K.C. \& Munshi, N.C. (2009a) A high-affinity fully human anti-IL-6 mAb, 1339, for the treatment of multiple myeloma. Clinical Cancer Research, 15, 7144-7152.

Fulciniti, M., Tassone, P., Hideshima, T., Vallet, S., Nanjappa, P., Ettenberg, S.A., Shen, Z., Patel, N., Tai, Y.T., Chauhan, D., Mitsiades, C., Prabhala, R., Raje, N., Anderson, K.C., Stover, D.R. \& Munshi, N.C. (2009b) Anti-DKK1 mAb (BHQ880) as a potential therapeutic agent for multiple myeloma. Blood, 114, 371-379.

Hayashi, T., Treon, S.P., Hideshima, T., Tai, Y.T., Akiyama, M., Richardson, P., Chauhan, D., Grewal, I.S. \& Anderson, K.C. (2003) Recombinant humanized anti-CD40 monoclonal antibody triggers autologous antibody-dependent cell-mediated cytotoxicity against multiple myeloma cells. British Journal of Haematology, 121, 592-596.

Heath, D.J., Chantry, A.D., Buckle, C.H., Coulton, L., Shaughnessy, Jr, J.D., Evans, H.R., Snowden, J.A., Stover, D.R., Vanderkerken, K. \& Croucher, P.I. (2009) Inhibiting Dickkopf-1 (Dkk1) removes suppression of bone formation and prevents the development of osteolytic bone disease in multiple myeloma. Journal of Bone and Mineral Research, 24, 425-436.

Hsi, E.D., Steinle, R., Balasa, B., Szmania, S., Draksharapu, A., Shum, B.P., Huseni, M., Powers, D., Nanisetti, A., Zhang, Y., Rice, A.G., van Abbema, A., Wong, M., Liu, G., Zhan, F., Dillon M., Chen, S., Rhodes, S., Fuh, F., Tsurushita, N., Kumar, S., Vexler, V., Shaughnessy, Jr, J.D., Barlogie, B., van Rhee, F., Hussein, M., Afar, D.E.H. \& Williams, M.B. (2008) CS1, a potential new therapeutic antibody target for the treatmen of multiple myeloma. Clinical Cancer Research, 14, 2775-2784.

Ikeda, H., Hideshima, T., Fulciniti, M., Lutz, R.J., Yasui, H., Okawa, Y., Kiziltepe, T., Vallet, S., Pozzi, S., Santo, L., Perrone, G., Tai, Y.T., Cirstea,
D., Raje, N.S., Uherek, C., Dalken, B., Aigner, S., Osterroth, F., Munshi, N., Richardson, P. \& Anderson, K.C. (2009) The monoclonal antibody nBT062 conjugated to cytotoxic maytansinoids has selective cytotoxicity against CD138-positive multiple myeloma cells in vitro and in vivo. Clinical Cancer Research, 15, 40284037.

Ishii, T., Chanan-Khan, A., Jafferjee, J., Ersing, N., Takahashi, H., Mizutani, M., Shiotsu, Y. \& Hanai, N. (2008) A humanized anti-ganglioside GM2 antibody, BIW-8962, exhibits ADCC/CDC activity against multiple myeloma cells and potent anti-tumor activity in mouse xenograft models. Blood (ASH Annual Meeting Abstracts), 112, Abstract 1718

Jagannath, S., Kyle, R.A., Palumbo, A., Siegel, D.S. Cunningham, S. \& Berenson, J. (2010) The current status and future of multiple myeloma in the clinic. Clinical Lymphoma, Myeloma and Leukemia, 10, 28-43.

Jakubowiak, A.J., Benson, Jr, D.M., Bensinger, W., Siegel, D.S., Zimmerman, T., Mohrbacher, A., Richardson, P., Afar, D.E.H., Singhal, A.K. \& Anderson, K.C. (2010) Elotuzumab in combination with bortezomib in patients with relapsed/ refractory multiple myeloma: updated results of a phase 1 study. Blood (ASH Annual Meeting Abstracts), 116, Abstract 3023.

Jemal, A., Siegel, R., Xu, J. \& Ward, E. (2010) Cancer statistics, 2010. CA: A Cancer Journal for Clinicians, 60, 277-300.

Kapoor, P., Greipp, P.T., Morice, W.G., Rajkumar, S.V., Witzig, T.E. \& Greipp, P.R. (2008) AntiCD20 monoclonal antibody therapy in multiple myeloma. British Journal of Haematology, 141, 135-148.

Kastritis, E., Charidimou, A., Varkaris, A. \& Dimopoulos, M.A. (2009) Targeted therapies in multiple myeloma. Targeted Oncology, 4, 23-36.

Kristinsson, S.Y., Landgren, O., Dickman, P.W., Derolf, A.R. \& Bjorkholm, M. (2007) Patterns of survival in multiple myeloma: a populationbased study of patients diagnosed in Sweden from 1973 to 2003. Journal of Clinical Oncology, 25, 1993-1999.

Kumar, S.K., Rajkumar, S.V., Dispenzieri, A., Lacy, M.Q., Hayman, S.R., Buadi, F.K., Zeldenrust, S.R., Dingli, D., Russell, S.J., Lust, J.A., Greipp, P.R., Kyle, R.A. \& Gertz, M.A. (2008) Improved survival in multiple myeloma and the impact of novel therapies. Blood, 111, 2516-2520.

Lonial, S., Vij, R., Harousseau, J.-L., Facon, T., Moreau, P., Leleu, X., Mazumder, A., Kaufman, J.L., Westland, C.E., Tsao, C., Singhal, A.K. \& Jagannath, S. (2010) Elotuzumab in combination with lenalidomide and low-dose dexamethasone in patients with relasped/refractory multiple myeloma: results of a phase 1 study. Blood (ASH Annual Meeting Abstracts), 116, Abstract 1936.

Lutz, R.J. \& Whiteman, K.R. (2009) Antibodymaytansinoid conjugates for the treatment of myeloma. Monoclonal Antibodies, 1, 548-551.

Mechtersheimer, G., Staudter, M. \& Möller, P. (1992) Expression of the natural killer (NK) cell- associated antigen CD56 (Leu-19), which is identical to the $140-\mathrm{kDa}$ isoform of $\mathrm{N}-\mathrm{CAM}$, in neural and skeletal muscle cells and tumors derived therefrom. Annals of the New York Academy of Sciences, 650, 311-316.

Mhaskar, R., Redzepovic, J., Wheatley, K., Clark, O.A., Miladinovic, B., Glasmacher, A., Kumar, A. \& Djulbegovic, B. (2010) Bisphosphonates in multiple myeloma. The Cochrane Database of Systematic Reviews, Issue 3. Art. No.: CD003188.

Moreau, P., Harousseau, J.-L., Wijdenes, J., Morineau, N., Milpied, N. \& Bataille, R. (2000) A combination of anti-interleukin 6 murine monoclonal antibody with dexamethasone and high-dose melphalan induces high complete response rates in advanced multiple myeloma. British Journal of Haematology, 109, 661-664.

Moreau, P., Hullin, C., Garban, F., Yakoub-Agha, I. Benboubker, L., Attal, M., Marit, G., Fuzibet, J.G., Doyen, C., Voillat, L., Berthou, C., Ketterer, N., Casassus, P., Monconduit, M., Michallet, M., Najman, A., Sotto, J.-J., Bataille, R., Harousseau, J.-L. \& for the Intergroupe Francophone du Myelome group (2006) Tandem autologous stem cell transplantation in high-risk de novo multiple myeloma: final results of the prospective and randomized IFM 99-04 protocol. Blood, 107, 397-403.

Moreaux, J., Hose, D., Reme, T., Jourdan, E. Hundemer, M., Legouffe, E., Moine, P., Bourin P., Moos, M., Corre, J., Mohler, T., De Vos, J., Rossi, J.F., Goldschmidt, H. \& Klein, B. (2006) CD200 is a new prognostic factor in multiple myeloma. Blood, 108, 4194-4197.

Niesvizky, R., Ely, S., Mark, T., Aggarwal, S., Gabrilove, J.L., Wright, J.J., Chen-Kiang, S. \& Sparano, J.A. (2011) Phase 2 trial of the histone deacetylase inhibitor romidepsin for the treatment of refractory multiple myeloma. Cancer, 117, 336-342.

Raschko, M., Markovina, S., Miyamoto, S., Longo, W., Williams, E., McFarland, T., Werndli, J., Wagner, E., Juckett, M. \& Callander, N. (2007) Phase II trial of bevacizumab combined with low dose dexamethasone and lenalidomide (BEV/ REV/DEX) for relapsed or refractory myeloma (MM). Blood (ASH Annual Meeting Abstracts), 110, Abstract 1173.

van Rhee, F., Szmania, S.M., Dillon, M., van Abbema, A.M., Li, X., Stone, M.K., Garg, T.K., Shi, J., Moreno-Bost, A.M., Yun, R., Balasa, B. Ganguly, B., Chao, D., Rice, A.G., Zhan, F., Shaughnessy, Jr, J.D., Barlogie, B., Yaccoby, S. \& Afar, D.E.H. (2009) Combinatorial efficacy of anti-CS1 monoclonal antibody elotuzumab (HuLuc63) and bortezomib against multiple myeloma. Molecular Cancer Therapeutics, 8 2616-2624.

van Rhee, F., Fayad, L., Voorhees, P., Furman, R., Lonial, S., Borghaei, H., Sokol, L., Crawford, J. Cornfeld, M., Qi, M., Qin, X., Herring, J., Casper, C. \& Kurzrock, R. (2010) Siltuximab, a novel anti-interleukin-6 monoclonal antibody, for Castleman's disease. Journal of Clinical Oncology, 28, 3701-3708. 
Richardson, P.G., Mitsiades, C., Schlossman, R., Munshi, N. \& Anderson, K. (2007) New drugs for myeloma. Oncologist, 12, 664-689.

Richardson, P.G., Moreau, P., Jakubowiak, A.J., Facon, T., Jagannath, S., Vij, R., Reece, D.E., White, D.J., Raab, M.S., Benboubker, L., Rossi, J.F., Tsao, C., Fry, J., Berman, D., Singhal, A.K. \& Lonial, S. (2010) Elotuzumab in combination with lenalidomide and dexamethasone in patients with relapsed multiple myeloma: interim results of a phase 2 study. Blood (ASH Annual Meeting Abstracts), 116, Abstract 986.

Robillard, N., Avet-Loiseau, H., Garand, R., Moreau, P., Pineau, D., Rapp, M.-J., Harousseau, J.-L. \& Bataille, R. (2003) CD20 is associated with a small mature plasma cell morphology and $\mathrm{t}(11 ; 14)$ in multiple myeloma. Blood, 102, 10701071.

Rosenblatt, J., Vasir, B., Uhl, L., Blotta, S., MacNamara, C., Somaiya, P., Wu, Z., Joyce, R., Levine, J.D., Dombagoda, D., Yuan, Y.E., Francoeur, K., Fitzgerald, D., Richardson, P., Weller, E., Anderson, K., Kufe, D., Munshi, N. \& Avigan, D. (2011) Vaccination with dendritic cell/tumor fusion cells results in cellular and humoral antitumor immune responses in patients with multiple myeloma. Blood, 117, 393-402.

Rossi, J.-F., Manges, R.F., Sutherland, H.J., Jagannath, S., Voorhees, P., Sonneveld, P., Delforge, M., Pegourie, B., Alegre, A., de la Rubia, J., La Police, D., Bandekar, R., Xie, H. \& Orlowski, R.Z. (2008) Preliminary Results of CNTO 328, An Anti-Interleukin-6 Monoclonal Antibody, in Combination with Bortezomib in the Treatment of Relapsed or Refractory Multiple Myeloma. Blood (ASH Annual Meeting Abstracts), 112, Abstract 867.

Rothenberg, M.L., Carbone, D.P. \& Johnson, D.H. (2003) Improving the evaluation of new cancer treatments: challenges and opportunities. Nature Reviews Cancer, 3, 303-309.

Salles, G., Seymour, J.F., Offner, F., Lopez-Guillermo, A., Belada, D., Xerri, L., Feugier, P., Bouabdallah, R., Catalano, J.V., Brice, P., Caballero, D., Haioun, C., Pedersen, L.M., Delmer, A., Simpson, D., Leppa, S., Soubeyran, P., Hagenbeek, A., Casasnovas, O., Intragumtornchai, T., Ferme, C., da Silva, M.G., Sebban, C., Lister, A., Estell, J.A., Milone, G., Sonet, A., Mendila, M., Coiffier, B. \& Tilly, H. (2011) Rituximab maintenance for 2 years in patients with high tumour burden follicular lymphoma responding to rituximab plus chemotherapy (PRIMA): a phase 3, randomised controlled trial. Lancet, 377, 42-51.

San Miguel, J.F., Schlag, R., Khuageva, N.K., Dimopoulos, M.A., Shpilberg, O., Kropff, M., Spicka, I., Petrucci, M.T., Palumbo, A., Samoilova, O.S., Dmoszynska, A., Abdulkadyrov, K.M., Schots, R., Jiang, B., Mateos, M.V., Anderson, K.C., Esseltine, D.L., Liu, K., Cakana, A., van de Velde, H. \& Richardson, P.G. (2008) Bortezomib plus melphalan and prednisone for initial treatment of multiple myeloma. New England Journal of Medicine, 359, 906-917.

Sapra, P., Stein, R., Pickett, J., Qu, Z., Govindan, S.V., Cardillo, T.M., Hansen, H.J., Horak, I.D. Griffiths, G.L. \& Goldenberg, D.M. (2005) AntiCD74 antibody-doxorubicin conjugate, IMMU110 , in a human multiple myeloma xenograft and in monkeys. Clinical Cancer Research, 11, 52575264 .

Shah, J.J., Zonder, J.A., Cohen, A., Weber, D. Thomas, S., Wang, M., Kaufman, J.L., Burt, S.M., Walker, D., Freeman, B., Rush, S.A., Ptaszynski, A., Orlowski, R.Z. \& Lonial, S. (2010) A phase I/II trial of the KSP inhibitor ARRY-520 in relapsed/ refractory multiple myeloma. Blood (ASH Annual Meeting Abstracts), 116, Abstract 1959.

Stevenson, G.T. (2006) CD38 as a therapeutic target. Molecular Medicine, 12, 345-346.

Tai, Y.T., Podar, K., Gupta, D., Lin, B., Young, G., Akiyama, M. \& Anderson, K.C. (2002) CD40 activation induces p53-dependent vascular endothelial growth factor secretion in human multiple myeloma cells. Blood, 99, 1419-1427.

Tai, Y.T., Podar, K., Mitsiades, N., Lin, B., Mitsiades, C., Gupta, D., Akiyama, M., Catley, L., Hideshima, T., Munshi, N.C., Treon, S.P. \& Anderson, K.C. (2003) CD40 induces human multiple myeloma cell migration via phosphatidylinositol 3-kinase/AKT/NF-kappa B signaling. Blood, 101, 2762-2769.

Tai, Y.T., Catley, L.P., Mitsiades, C.S., Burger, R., Podar, K., Shringpaure, R., Hideshima, T. Chauhan, D., Hamasaki, M., Ishitsuka, K., Richardson, P., Treon, S.P., Munshi, N.C. \& Anderson, K.C. (2004) Mechanisms by which SGN-40, a humanized anti-CD40 antibody, induces cytotoxicity in human multiple myeloma cells: clinical implications. Cancer Research, 64, 2846-2852.

Tai, Y.T., Li, X.F., Catley, L., Coffey, R., Breitkreutz, I., Bae, J., Song, W., Podar, K., Hideshima, T., Chauhan, D., Schlossman, R., Richardson, P., Treon, S.P., Grewal, I.S., Munshi, N.C. \& Anderson, K.C. (2005a) Immunomodulatory drug lenalidomide (CC-5013, IMiD3) augments anti-CD40 SGN-40-induced cytotoxicity in human multiple myeloma: clinical implications. Cancer Research, 65, 11712-11720.

Tai, Y.T., Li, X., Tong, X., Santos, D., Otsuki, T. Catley, L., Tournilhac, O., Podar, K., Hideshima, T., Schlossman, R., Richardson, P., Munshi, N.C., Luqman, M. \& Anderson, K.C. (2005b) Human anti-CD40 antagonist antibody triggers significant antitumor activity against human multiple myeloma. Cancer Research, 65, 5898-5906.

Tai, Y.T., Dillon, M., Song, W., Leiba, M., Li, X.F., Burger, P., Lee, A.I., Podar, K., Hideshima, T., Rice, A.G., van Abbema, A., Jesaitis, L., Caras, I., Law, D., Weller, E., Xie, W., Richardson, P., Munshi, N.C., Mathiot, C., Avet-Loiseau, H., Afar, D.E. \& Anderson, K.C. (2008) Anti-CS1 humanized monoclonal antibody HuLuc63 inhibits myeloma cell adhesion and induces antibody-dependent cellular cytotoxicity in the bone marrow milieu. Blood, 112, 1329-1337.

Tassone, P., Gozzini, A., Goldmacher, V., Shammas, M.A., Whiteman, K.R., Carrasco, D.R., Li, C., Allam, C.K., Venuta, S., Anderson, K.C. \& Munshi, N.C. (2004a) In vitro and in vivo activity of the maytansinoid immunoconjugate huN901-N2'-deacetyl-N2'-(3-mercapto-1-oxopropyl)-maytansine against $\mathrm{CD} 56+$ multiple myeloma cells. Cancer Research, 64, 4629-4636.

Tassone, P., Goldmacher, V.S., Neri, P., Gozzini, A., Shammas, M.A., Whiteman, K.R., HylanderGans, L.L., Carrasco, D.R., Hideshima, T., Shringarpure, R., Shi, J., Allam, C.K., Wijdenes, J., Venuta, S., Munshi, N.C. \& Anderson, K.C. (2004b) Cytotoxic activity of the maytansinoid immunoconjugate B-B4-DM1 against CD138+ multiple myeloma cells. Blood, 104, 3688-3696.

Trikha, M., Corringham, R., Klein, B. \& Rossi, J.F. (2003) Targeted anti-interleukin-6 monoclonal antibody therapy for cancer: a review of the rationale and clinical evidence. Clinical Cancer Research, 9, 4653-4665.

Veikkola, T., Karkkainen, M., Claesson-Welsh, L. \& Alitalo, K. (2000) Regulation of angiogenesis via vascular endothelial growth factor receptors. Cancer Research, 60, 203-212.

Vij, R., Horvath, N., Spencer, A., Taylor, K., Vadhan-Raj, S., Vescio, R., Smith, J., Qian, Y., Yeh, H. \& Jun, S. (2009) An open-label, phase 2 trial of denosumab in the treatment of relapsed or plateau-phase multiple myeloma. American Journal of Hematology, 84, 650-656.

Voorhees, P.M., Chen, Q., Small, G.W., Kuhn, D.J., Hunsucker, S.A., Nemeth, J.A. \& Orlowski, R.Z. (2009) Targeted inhibition of interleukin-6 with CNTO 328 sensitizes pre-clinical models of multiple myeloma to dexamethasone-mediated cell death. British Journal of Haematology, 145, 481-490.

Weber, D.M., Chen, C., Niesvizky, R., Wang, M., Belch, A., Stadtmauer, E.A., Siegel, D., Borrello, I., Rajkumar, S.V., Chanan-Khan, A.A., Lonial, S., Yu, Z., Patin, J., Olesnyckyj, M., Zeldis, J.B. \& Knight, R.D. (2007) Lenalidomide plus dexamethasone for relapsed multiple myeloma in North America. New England Journal of Medicine, 357, 2133-2142.

Weiner, L.M., Surana, R. \& Wang, S. (2010) Monoclonal antibodies: versatile platforms for cancer immunotherapy. Nature Reviews Immunology, 10, 317-327.

Yoshio-Hoshino, N., Adachi, Y., Aoki, C., Pereboev, A., Curiel, D.T. \& Nishimoto, N. (2007) Establishment of a new interleukin-6 (IL-6) receptor inhibitor applicable to the gene therapy for IL-6dependent tumor. Cancer Research, 67, 871-875.

Zonder, J.A., Singhal, S., Bensinger, W., Mohrbacher, A., Hussein, M.A., Munshi, N.C., Caras, I., Singhal, A. \& van Rhee, F. (2008) Phase I study of elotuzumab (HuLuc63) in relapsed/refractory multiple myeloma. Blood (ASH Annual Meeting Abstracts), 112, Abstract 2773. 